\title{
ASPECTOS HISTÓRICOS DOS PLANOS NACIONAIS DE EDUCAÇÃO DO BRASIL: DA DÉCADA DE 30 À DE 80
}

\author{
Ítalo Batista da Silva ${ }^{1}$ e Ed Francklin da Silva ${ }^{2}$ \\ ${ }^{1}$ Graduando em Licenciatura Plena em Física no CEFET-RN \\ ibsfisica@hotmail.com \\ ${ }^{2}$ Graduando em Licenciatura Plena em Física no CEFET-RN. \\ edinho32@hotmail.com
}

Recebido em fevereiro de 2006 e aceito em maio de 2006

\begin{abstract}
RESUMO
Este trabalho apresenta os aspectos históricos dos Planos Nacionais de Educação do Brasil, desde a década de 30 (criação do Ministério da Educação) à de 80, através de levantamento bibliográfico, limitando-se a destacar as principais características do período em estudo. A idéia de Plano de Educação surge com os primeiros manifestos, introduzindo a racionalidade científica no campo de ensino, voltado para a manipulação das classes subalternas (contenção social - política do Estado Novo). No ano de 1961, é promulgada a Lei de Diretrizes e Bases (LDB), com novas concepções para a educação brasileira. Entre 1962 e 1985 ( período do Golpe Militar), ocorrem mudanças significativas na idéia de Planejamento Educacional, que se transforma em um mero instrumento de racionalidade tecnocrática - concepção tecnicista da educação, sem qualquer participação da sociedade no processo educacional. Os planos para a educação estavam diretamente ligados aos Planos Nacionais de Desenvolvimento (PNDs) e ao capitalismo, que planeja todos os setores da sociedade, inclusive o planejamento educacional, que tem como uma de suas principais metas reduzir o índice de pobreza.
\end{abstract}

Palavras-chave: Aspectos históricos dos Planos Nacionais de Educação; racionalidade científica; Lei de Diretrizes e Bases da Educação e concepção tecnicista da educação.

\section{HISTORICAL ASPECTS OF BRAZILIAN NATIONAL PLANS OF EDUCATION: FROM THE 30 TO THE 80 DECADES}

\begin{abstract}
This work presents the historical aspects of the National Plans of Education of Brazil, since the decade of 30 (creation of the Education Ministry) to the 80, through bibliographical survey, limiting to detach the main characteristics of the period in study. The idea of plan appeared with the First Manifests, introducing the scientific rationality in education field, come back toward the manipulation of subordinate (social containment - politics of the New State). In the year of 1961 is promulgated the Law of Lines of Direction and Bases (LDB), with new conceptions for the Brazilian education. Between 1962 and 1985 (Military Regime), occurred significant changes in the idea of Educational Planning, that technicist conception of the education is transformed into a mere instrument of technocratic rationality - technicist conception of the education, without any participation of the society in the educational process. The plans for the education were directly on to the National Plans of Development (PNDs), to the capitalism that plans all the sectors of
\end{abstract}


the society, also the educational planning, that it has as one of its main goals to reduce the poverty index.

Keywords: historical aspects of the National Plans of Education; scientific rationality; Law of Lines of direction and Bases of the education and technicist conception of the education. 


\section{ASPECTOS HISTÓRICOS DOS PLANOS NACIONAIS DE EDUCAÇÃO DO BRASIL: DA DÉCADA DE 30 À DE 80}

\section{INTRODUÇÃO}

O principal objetivo deste trabalho é fazer um levantamento dos antecedentes históricos dos Planos Nacionais de Educação do Brasil, desde a década de 30 até a de 80 . As fontes bibliográficas mostram que é na década de 30 a de 40 que aparece a idéia de plano Nacional de Educação com os manifestos dos pioneiros na Educação Nova.. A política educacional do período de 1946-1962 reflete os conflitos de poderes existentes no país: um conflito em torno da criação da LDB (Lei de Diretrizes e Bases). E por final, no período de 1962 a 1985 (Golpe Militar), a idéia de Planejamento Educacional transforma-se num instrumento de racionalidade tecnocrática - concepção tecnicista da educação, sem qualquer participação da sociedade no processo educacional.

O Brasil é um país marcado por exclusões sociais ao longo de toda a sua história, em qualquer esfera da sociedade: saúde, educação, moradia, entre outros. No processo educacional, encontramos um dos maiores exemplos dessas exclusões, que remonta desde o Brasil colônia, em que o sistema educacional era quase inexistente, já que não havia demanda da estrutura social e de produção, não havendo assim necessidade de uma abordagem escolar. As funções de reprodução da ideologia dominante e das relações de dominação eram cumpridas pelas escolas jesuítas. Ainda no Império e I República, a Igreja continuou controlando as instituições de ensino, não alterando substancialmente as funções de educação em relação ao período colonial.

\section{ANTECEDENTES DOS PLANOS NACIONAIS DE EDUCAÇÃO DO BRASIL: DA DÉCADA DE 30 À DE 80.}

O Brasil é um país capitalista subdesenvolvido, marcado ao longo de sua história por exclusões sociais, com elevada dívida social, seja ela em qualquer plano (educação, saúde, entre outros). O planejamento da educação encontra-se nesta linha de exclusões sociais, estando inteiramente relacionado ao desenvolvimento da sociedade de toda e qualquer nação do mundo. Também está mais inteiramente ligada ao planejamento do capitalismo, com o plano econômico, pois o desenvolvimento do capital influencia o progresso da educação no tocando no Brasil com o mundo. Calazans (2001, p.13) destaca: “o planejamento num sistema capitalista não é mais a forma de racionalização da reprodução ampliada do capital; fica, portanto, claro que não é o planejamento que planeja o capitalismo, mas é o capitalismo que planeja o planejamento”.

É interessante ressaltar o significado do termo planejamento no dicionário Aurélio (1986, p. 1343), considerando:

1. Ato ou efeito de planejar. 2. Trabalho de preparação para qualquer empreendimento, segundo roteiro e métodos determinados; planificação: o planejamento de um livro, de uma comemoração. 3. Elaboração, por etapas, com bases técnicas (especialmente no campo sócio-econômico), de planos e programas com objetivos definidos.

Com isso, o planejamento educacional, ou melhor, um Plano Nacional de Educação brasileiro objetiva o desenvolvimento sócio-econômico do país, combatendo a pobreza em todos os setores sociais da nação. A educação tem como uma das metas principais o desenvolvimento social, criando programas para diminuir os índices de pobreza, 
desigualdade e desemprego. Esse planejamento educacional do país está em total acordo e atrelação/relação com a discussão da questão educacional na Nova República que integra as estratégias do I Plano Nacional de Desenvolvimento (I PND).

É na década de 1930 que surge a idéia de plano no âmbito educacional brasileiro, que segundo Saviani (2002, p.72), "provavelmente a sua primeira manifestação explícita nos é dada pelo Manifesto dos Pioneiros da Educação Nova, lançado em 1932”. Esse "Manifesto" fez um diagnóstico da educação pública brasileira e mostrou o imperativo de se criar um sistema de organização escolar que estivesse de acordo com as necessidades do país, aproximando a idéia de Plano de Educação relacionado com o pensamento de sistema educacional organizado de forma racionalista (lógica), com o conjunto de atividades educativas coerente e eficaz para uma determinada sociedade.

Continuando a periodização do Plano Nacional de Educação, a Constituição Brasileira de 1934 recebeu influência desses primeiros movimentos, ligada ao conceito de Plano, interpretada como um mero método de introdução no campo da educação e da racionalidade científica. No artigo 150 (publicado em 1934), alínea “a” estabeleceu-se como competência da União "fixar o plano nacional de educação, compreensivo do ensino de todos os graus e ramos, comuns e especializados, coordenar e fiscalizar a sua execução, em todo o território do país” (SAVIANI 2002, op.cit. p.73). Nesta mesma Constituição também se previa um Conselho Nacional de Educação, tendo como principal função elaborar o Plano Nacional de Educação, cujo documento foi formulado pelos conselheiros em 1937. Entretanto, com o advento do Estado Novo, nesse mesmo ano, esse documento acabou por ser deixado de lado. Freitag (1979, p.50), coloca que "a política educacional do Estado Novo não se limita à simples legislação e sua implantação. Essa política visa, acima de tudo, transformar o sistema educacional em um instrumento mais eficaz de manipulação das classes subalternas”.

Dermeval Saviani (2002, op.cit. p.74), destaca que "do ponto de vista da forma, o referido Plano correspondia ao espírito da Constituição de 1934, já que aí, como se assinalou, a idéia de plano coincidia com as próprias diretrizes e bases da educação nacional”. O conteúdo desse plano afastava-se da idéia dos pioneiros, aproximando-se à orientação que irá predominar no Estado Novo (1937 - 1945). Freitag (1979 op.cit.) destaca sobre esse momento que passou o Brasil da seguinte forma:

Com o auxílio de certos grupos militares (tenentes) e apoiado pela classe burguesa, Vargas assume o poder em 1930, implantando, em 1937, o Estado Novo, com traços ditatoriais. Isto significa que a sociedade política invade áreas da sociedade civil, subordinando-as ao seu controle. É o que ocorrerá com as instituições de ensino. Percebe-se uma intensa atividade do Estado em ambas as instâncias da superestrutura. É criado pela primeira vez, em 1930, um ministério da Educação e Saúde, ponto de partida, segundo Valnir Chagas, para mudanças substanciais na educação, entre outras a estrutura de uma universidade. (FREITAG, 1979 op.cit.p.48)

Neste período de 1930 a 1945, começa a ocorrer intensa participação do Estado na sociedade política e civil pelo (a Igreja perde importância no campo educacional, visto que passou a ser política de Estado), criando-se no cenário educacional o ministério da educação e a estruturação de algumas Universidades (FREITAG 1979 op.cit.). A constituição de 1930 previa um Plano Nacional de Educação, garantindo o ensino primário gratuito e obrigatório, enquanto o religioso passava a ser facultativo. Enquanto na de 1937, previa-se a introdução do ensino profissionalizante, entre outros. 
O Plano de Educação era entendido pelos educadores alinhados com o movimento renovador como um instrumento de introdução do racionalismo científico na política educacional, enquanto que para Getúlio Vargas, significava converter um instrumento destinado a revestir de racionalidade o controle político-pedagógico exercido através da política educacional. O sistema educacional tinha a finalidade de manipular as forças subalternas, pois a classe trabalhadora passava a ter acesso à escola, mas o tipo de oferta não possibilitava a mobilidade social.

Entre 1946 e 1964, percebe-se uma tensão entre duas visões de Plano de educação, como mostra Dermeval Saviani (2002 op.cit),

Expressa a contradição entre as forças que se aglutinaram sob a bandeira do nacionalismo desenvolvimentista que atribuíam ao Estado a tarefa de planejar o desenvolvimento do país, libertando-o da dependência externa, a aquelas que defendiam a iniciativa privada, contrapondo-se à ingerência do Estado na economia e àquilo que taxavam de monopólio estatal de ensino. Essas duas tendências repercutiram no debate que se travou por ocasião da discussão no Congresso do projeto Lei de Diretrizes e Bases da Educação Nacional. (SAVIANI, 2002 op.cit.p.75)

$\mathrm{Na}$ primeira tendência, salientou-se a necessidade de o projeto de LDB originar as condições para a construção de um sistema de ensino voltado às necessidades do desenvolvimento brasileiro e também voltado para a realidade do Brasil, o que criticado por Santiago Dantas, que introduziu o debate na Câmara dos Deputados, na sessão de 04/06/1959, por que, o projeto de LDB ser apenas uma consolidação das leis do ensino. Entretanto, nas discussões travadas sobre a LDB, prevaleceu a segunda tendência, que defendia o direito da liberdade de ensino, na qual a família tinha o direito de escolher o tipo de educação dos seus filhos. Saviani (2002 op.cit.p.75) enfatiza que "em decorrência dessa orientação, a idéia de Plano de Educação na nossa primeira LDB ficou reduzida à instrumentação de distribuição de recursos para os diferentes níveis de ensino. De fato, pretendia-se que o Plano garantisse o acesso das escolas particulares, em especial as católicas, aos recursos públicos destinados à educação”.

A Lei de Diretrizes e Bases da Educação Nacional foi promulgada em 20 de Dezembro de 1961. Essa Lei faz referência ao Planejamento de Educação, estabelecendo que nove décimos das verbas federais seriam destinadas à educação, em parcelas iguais para os três Fundos Nacionais de Educação (Ensino Primário, Ensino Médio e Ensino Superior). O planejamento foi elaborado pelo Conselho Federal de Educação cujo documento de 1962 estabeleceu as normas para a aplicação dos recursos correspondentes aos Fundos de Ensino Primário, do Ensino Médio e do Ensino superior e definiu-se que os recursos Constitucionais vinculados à educação seriam destinados à manutenção e desenvolvimento do sistema público de ensino.

Em síntese, de 1932 a 1962, o Planejamento Educacional no Brasil, era entendido, grosso modo, como um instrumento de introdução do racionalismo científico na educação, sob a ótica de uma escola nova (escolanovista). No período que se segue, de 1962 até 1985, o Planejamento Educacional transforma-se num instrumento de racionalidade tecnocrática concepção tecnicista da educação. Tal planejamento veio, segundo Aranha (1996), prejudicar as escolas públicas, exacerbando a burocratização do ensino com preenchimento de papéis e controle das atividades, além de ignorar as especificidades do processo pedagógico, reduzindo o professor a simples executor de tarefas organizadas no âmbito do planejamento. 
Em 1964, devido à polarização entre as forças populares/populistas e os interesses das classes hegemônicas nacionais e internacionais, resultou o golpe militar, com a instalação dos governos militares que revezaram de 1964 a 1985. Nessa época, a escola é utilizada como veículo de inculcação dos ideais da "revolução" (Brasil: ame-o ou deixe-o). Também nesse mesmo período transfere-se o protagonismo do Planejamento Educacional dos educadores para os tecnocratas, isso, em termos organizacionais, visto que o Ministério da Educação é subordinado ao Ministério do Planejamento, cujos corpos técnico e dirigente, eram oriundos da área de Ciências Econômicas. Dessa forma, os Planos para a educação estavam diretamente ligados aos Planos Nacionais de Desenvolvimento (PNDs) do país, ganhando a denominação de Planos Setoriais de Educação e Cultura. Isto mostra que o Planejamento Setorial da Educação estava relacionado por lei às diretrizes e normas do Plano Geral do Governo.

De 1986 a 1989, o Brasil passa pelo período da Nova República, que elaborou o I Plano Nacional de Desenvolvimento da Nova República, utilizando o Plano Educação para Todos (que o Governo Tancredo queria para a educação nacional), como uma formulação de políticas, planejamento e gestão tecnocrática.

No ano de 1993, foi editado um plano elaborado pelo MEC - Plano Decenal de Educação para Todos - que pretendia distinguir-se dos planos anteriores, visto que não se referia à educação como um todo, mas apenas à educação fundamental, procurando encontrar os caminhos para diagnosticar o ensino fundamental e procurar também soluções para enfrentar esses obstáculos, formulando estratégias para erradicar o analfabetismo, bem como universalizar a educação fundamental, abrangendo, dessa forma, a educação infantil (pré-escolar). Mesmo que esse plano se propusesse a enfrentar os problemas da educação, como muitos dos planejamentos educacionais do Brasil, ele praticamente não saiu do papel. Para Dermeval Saviani (2002 op.cit.p.78), “em verdade, ao que parece, o mencionado Plano foi formulado mais em função do objetivo pragmático de atender a condições internacionais de obtenção de financiamento para a educação, em especial aquele de algum modo ligado ao Banco Mundial”.

É importante considerar que o MEC apresentou um Plano para a educação brasileira, que explicitamente, é uma mera continuidade do Plano Decenal de Educação para Todos de 1993, e mais recentemente, no ano de 1996, foi elaborado o atual Plano Nacional de Educação do Brasil.

\section{CONCLUSÃO}

A idéia de plano no âmbito do sistema educacional brasileiro surge somente na década de 1930 (nesse período cria-se o ministério da educação), apesar de que, desde o nosso descobrimento, com as escolas jesuítas, se tenha obtido a primeira estruturação de reprodução ideológica (política educacional inexistente). O Brasil é uma nação que, ao longo de todo o seu processo histórico, é marcado por sucessivas exclusões no cenário social, sendo um desses principais problemas o sistema educacional, cuja meta principal é o desenvolvimento social, criando programas para combater as desigualdades, a pobreza e o desemprego no país. Os primeiros Manifestos da Educação Nova aparecem em 1932 (certamente a primeira expressão pública de educação), influenciando a Constituição Brasileira de 1934 a elaborar um Plano Nacional de Educação (compreensivo do ensino de todos os graus e ramos). 
Com o advento do Estado Novo, muita coisa mudou no Planejamento da Educação, que deixou de ser um mero instrumento de introdução à racionalidade científica, para transforma-se em um meio destinado a revertir de racionalidade o controle políticopedagógico exercido através da política educacional. Entre 1946 e 1962, o plano nacional de educação foi marcado por duas visões para a construção do projeto de LDB. Na primeira tendência, salientava-se a necessidade da construção de um sistema de ensino voltado para o desenvolvimento brasileiro. Nessa discussão, acabou por prevalecer a segunda visão, que dava às famílias o direito de decidir sobre o tipo de educação de seus filhos.

Promulgada em 1961, a LDB, referindo-se ao Planejamento da Educação, reduzia-se à instrumentação de distribuição de recursos destinados à manutenção e desenvolvimento do sistema público de ensino em seus diferentes níveis de ensino. No período de 1962 até 1985, ocorrem significativas mudanças no cenário político (Golpe Militar) e educacional, transformando a educação em um mero instrumento de racionalidade tecnicista, sem qualquer interferência ou participação da sociedade no processo ou sistema de educação, o que também reduziu o professor a um executor de tarefas simples, prejudicando as escolas em geral no processo de ensino-aprendizagem.

A partir das características levantadas para cada um dos períodos em estudo, conclui-se que atrasos e progressos ocorreram, segundo os Planos Nacionais de Educação estavam direcionados às necessidades do país.

\section{BIBLIOGRAFIA CONSULTADA}

ARANHA, M. L. A. História da educação. 2 ed. Rev. e Atual. São Paulo: Moderna, 1996.

CALAZANS, M. J. C. Planejamento e educação no Brasil - novas estratégias em busca de novas concepções. In: KUENZER, A. CALAZANS, M. J. C.; GARCIA, W. Planejamento e Educação no Brasil. 6 ed.. São Paulo: Cortez, 2000 (coleção questões da Nossa Época, v.21), p. 35-54.

DERMEVAL, S. Plano nacional de educação: antecedentes históricos. In: Da Nova LDB ao Novo Plano Nacional de educação: por uma outra política educacional. Campinas - SP: Autores associados, 2002 (coleção educação contemporânea). p. 73-78.

FREITAG, B. Política educacional: uma retrospectiva histórica. In: Escola, estado e sociedade. 3 ed.. São Paulo: Cortez \& Moraes, 1979, p. 43-69.

FERREIRA, A. B. H. Novo Dicionário Aurélio: Novo Dicionário da Língua Portuguesa. 2 ed. rev. e ampl. Rio de Janeiro: editora Nova Fronteira, 1986, p. 1343.

GARCIA, W. E. Planejamento e educação no Brasil: a busca de novos caminhos. In: KUENZER, A. CALAZANS, M. J. C.; GARCIA, W. Planejamento e Educação no Brasil. 6 ed.. São Paulo: Cortez, 2000 (coleção questões da Nossa Época, v.21), p. 35-54.

KUENZER, A. Z. Política Educacional e Planejamento no Brasil: os descaminhos da transição. In: KUENZER, A. CALAZANS, M. J. C.; GARCIA, W. Planejamento e Educação no Brasil. 6 ed.. São Paulo: Cortez, 2000 (coleção questões da Nossa Época, v.21), p. 55-89. 